\title{
Fungsi Eksekutif dan Bahasa: Tinjauan Meta-analisis
}

\author{
Heru Astikasari Setya Murti \\ Program Studi Psikologi, Fakultas Psikologi Universitas Satyawacana, Salatiga
}

\begin{abstract}
School readiness is very crucial for achieving children's school success. Language, in both the ability to understand and the use of language, is one of important aspect of school readiness. Language itself is strongly influenced by executive function. Although many studies have found that executive function is closely related to language development, some studies still find uncertainty in the relationship between them. The purpose of this research is to study the integrative findings of a number of studies to elicit stronger patterns of relationships from previous research by using meta-analysis methods. There are 28 studies are including in this meta-analysis study, and artifact allow for correction is sampling error (bare bones metaanalysis).The results of this meta-analysis study shows that the correlation of executive function and language is 0.318 , with the confidence level is $95 \%$.
\end{abstract}

Keywords: executive function, language, meta-analysis, school readiness

\begin{abstract}
Abstrak. Kesiapan sekolah sangat diperlukan agar keberhasilan pendidikan di sekolah dapat tercapai. Bahasa, baik kemampuan memahami maupun menggunakan bahasa, merupakan salah satu aspek penting dalam kesiapan sekolah. Bahasa sendiri sangat dipengaruhi oleh fungsi eksekutif (executive function). Meski telah banyak penelitian yang menemukan bahwa fungsi eksekutif sangat erat kaitannya dengan perkembangan bahasa, beberapa penelitian masih menemukan ketidakjelasan hubungan di antara keduanya. Tujuan dari penelitian ini adalah mengaji secara integratif temuan dari sejumlah studi untuk memunculkan pola-pola hubungan yang lebih kokoh dari penelitian terdahulu dengan menggunakan metode metaanalisis. Ada 28 studi yang digunakan dalam meta-analisis ini, dan artefak yang digunakan untuk koreksi adalah kesalahan sampling (bare bones meta-analysis). Hasil studi meta-analisis ini menunjukkan hubungan antara fungsi eksekutif dengan bahasa sebesar 0,318, dengan tingkat kepercayaan 95\%.
\end{abstract}

Kata kunci: fungsi eksekutif, bahasa, kesiapan sekolah, meta-analisis

Korespondensi: Heru Astikasari Setya Murti. E-mail: heru.astika@gmail.com 
Pendidikan memiliki peranan yang penting dalam pembentukan diri individu dan meningkatkan kualitas sumber daya manusia (SDM), sebab melalui pendidikan, kesejahteraan anak dan masyarakat akan dapat dicapai. Pendidikan dapat ditempuh salah satunya melalui pendidikan formal di sekolah. Agar dapat mencapai keberhasilan dalam pendidikan di sekolah, salah satu faktor yang sangat memengaruhi adalah kesiapan sekolah (school readiness) yang dimiliki oleh anak (Grove \& Hauptfleisch, 2005). United Nations Emergency Children's Fund (UNICEF) menyebutkan bahwa kesiapan sekolah merupakan strategi yang telah terbukti untuk meningkatkan pembangunan ekonomi dan sosial sebuah masyarakat (Grove \& Hauptfleisch, 2005). Kesiapan sekolah penting karena menjadi dasar bagi kehidupan yang lebih baik untuk individu, komunitas maupun masyarakat. Anak yang memiliki kesiapan sekolah mampu mengikuti proses pendidikan di sekolah sehingga diprediksikan akan mencapai kesuksesan sekolah (Fitzpatrick, 2012). Salah satu aspek penting dalam kesiapan sekolah adalah bahasa. Seperti yang dinyatakan Blair dan Razza (2007) bahwa penguasaan bahasa, baik kemam-puan memahami maupun menggunakan bahasa, merupakan salah satu kunci keberhasilan sekolah. Selama masa kanak-kanak dan tahun-tahun prasekolah, kemampuan untuk memahami, memproses dan menghasilkan bahasa berkembang dengan pesat (Stackhouse, 1997). Kemampuan ini menjadi dasar bagi perkembangan bahasa tahap selanjutnya dan bagi pencapaian prestasi akademik di sekolah.

Bahasa merupakan sebuah sistem aturan yang digunakan untuk mengomunikasikan ide, keinginan, dan kebutuhan, yang secara umum dapat dibagi dalam dua kategori, yaitu bahasa reseptif misalnya mendengarkan, pemahaman dan bacaan, dan bahasa ekspresif misalnya bicara, gesture, dan menulis (Stackhouse, 1997). Lebih lanjut Stackhouse menjelaskan bahwa sebagai konstruk yang komprehensif, bahasa melibatkan beragam kompetensi yang saling terkait, meliputi perbenda-haraan kata, sintaks, dan proses pembelajaran bahasa. Sebagai contoh, perbendaharaan kata terdiri dari kata-kata yang mampu dipahami dan dihasilkan oleh anak. Komponen bahasa ini adalah penting karena memberikan dasar pengetahuan yang membantu anak agar dapat berhasil beradaptasi dengan lingkungannya, melalui pemberian label dan atribut untuk diorganisasi serta memberikan referensi mengenai konsep-konsep yang dihadapi anak dalam kehidupan sehari-hari.

Peran penting bahasa dalam bidang akademik dipertegas oleh Muter, Hulme, Snowling, dan Stevenson (2004) yang menyebutkan bahwa bahasa reseptif memberikan dasar bagi semua capaian prestasi. Dalam hal ini, jelas bahwa 
kemampuan anak untuk memahami dan menerima konsep penting bagi keberhasilan sekolah. Keterampilan ini membantu anak untuk memahami aturan kelas, mengikuti instruksi verbal dan berpartisipasi secara tepat dalam interaksi sosial. Selain itu, keterampilan praliterasi (seperti mengenali huruf dan pemahaman mengenai keterhubungan antara bunyibunyi huruf) merupakan prediktor yang baik dari kemampuan membaca anak selama mengikuti sekolah. Tidak hanya bahasa reseptif, anak juga perlu menggunakan bahasa ekspresif untuk mendeskripsikan peristiwa-peristiwa yang telah terjadi, menceritakan mengenai pengalaman, dan membuat prediksi mengenai apa yang akan terjadi di masa mendatang. Bahasa juga akan membantu anak untuk mengembangkan kemampuan kognitif dan pengetahuan secara lebih jauh sehingga menjadi siswa yang efektif (Blair \& Razza, 2007).

Tannock dan Schachar (1996) menyebutkan bahwa bahasa dipengaruhi oleh fungsi eksekutif (executive function). Fungsi eksekutif penting dalam proses perkembangan bahasa terkait dengan perannya dalam proses organisasional yang terlibat di berbagai level pembelajaran bahasa (Guralnick, 2011). Secara umum fungsi eksekutif didefinisikan sebagai kemampuan untuk mengontrol dan mengelola proses kognitif dan perilaku, yang biasanya dilihat sebagai proses yang digunakan untuk regulasi diri atas pemikiran dan perilaku dalam rangka mencapai tujuan (Ursache, Blair, \& Raver, 2012). Menurut Hughes dan Graham (2002), fungsi eksekutif merujuk pada sekumpulan proses regulasi kognitif, meliputi working memory, inhibitory control dan cognitive flexibility yang memampukan dilakukannya pengorganisasian pikiran dan perilaku. Kendall-Taylor, Erard, Davey dan Simon (2010) menyebutkan bahwa working memory merupakan kemampuan untuk bekerja dengan beragam informasi secara bersamaan, inhibitory control merupakan kemampuan untuk tidak berperilaku secara otomatis, mengontrol diri dan tidak mudah terganggu oleh stimulus lingkungan, sedangkan cognitif flexibility adalah kemampuan untuk mengubah cara berpikir, seperti mengubah perilaku untuk disesuaikan dengan situasi yang berbeda, atau melihat sesuatu dari perspektif yang berbeda. Seperti halnya bahasa, keterampilan-keterampilan fungsi eksekutif ini berkembang pesat selama masa pra sekolah dan tahun-tahun awal sekolah dasar yakni usia 3-7 tahun (Blair, 2002).

Terkait dengan peran fungsi eksekutif dalam perkembangan bahasa, Engle (2010) menyebutkan bahwa komponen fungsi eksekutif yaitu working memory bertanggung jawab dalam mempertahankan informasi selama jangka waktu tertentu (memori jangka pendek). Komponen cognitive flexibility berperan 
meregulasi dan mengoordinasi informasi yang diterima sehingga dapat digunakan sesuai dengan kebutuhan akan penggunaannya. Kemudian, disebutkan oleh Ye dan Zhou (2008) bahwa inhibitory control memungkinkan pendengar untuk memilih satu dari berbagai macam interpretasi sebagai respon dari sebuah pesan yang disampaikan dan erat kaitannya dengan pemahaman bahasa. Sebagai tambahan, Simlesa, Cepanec, dan Ljubesic (2017) memaparkan bahwa inhibitory control dan cognitive flexibility membantu anak meningkatkan kemampuannya dalam beradaptasi dengan tugas-tugas deskriptif linguistik dan kemampuan adaptasi dalam memaknai perubahan pesan-pesan verbal.

Penelitian-penelitian yang ada telah menunjukkan bahwa perkembangan awal bahasa bergantung pada proses fungsi eksekutif (Verhagen \& Leseman, 2016). Penelitian yang berfokus pada peran working memory dalam pemerolehan bahasa menemukan bahwa kemampuan untuk memperbarui informasi dalam working memory akan berkontribusi terhadap penguasaan kosakata anak (Morra \& Cammba, 2009), sementara cognitive flexibility yang meregulasi dan mengoordinasi penerimaan informasi dapat membantu memfasilitasi pembelajaran bahasa (Bishop, Nation, \& Patterson, 2014). Intervensi yang dilakukan pada fungsi eksekutif juga membantu meningkatkan keterampilan bahasa anak prasekolah
(Rojas-Barahona, Förster, Moreno-Rios, \& McCleland, 2015). Di sisi lain, ditemukan pula bahwa lemahnya fungsi eksekutif berdampak pada buruknya bahasa pada anak (Henry, Messerm \& Nash, 2012).

Sebagian besar penelitian menemukan bahwa fungsi eksekutif sangat erat kaitannya dengan perkembangan bahasa, sedangkan sebagian kecil lainnya menemukan ketidakjelasan tingkat hubungan fungsi eksekutif dengan perkembangan bahasa (Diamond, 2013). Terkait dengan hal tersebut maka diperlukan kajian yang mampu mengintegrasikan temuan dari sejumlah studi untuk memunculkan polapola hubungan yang lebih jelas dari penelitian terdahulu (Hunter \& Schmidt, 2014). Oleh karena itu, pengujian hipotesis dilakukan dengan menggunakan metaanalisis sebagai metode supaya dapat melakukan estimasi mengenai tingkat hubungan dari penelitian-penelitian yang telah dilakukan. Adapun hipotesis yang diajukan adalah ada hubungan antara fungsi eksekutif dan bahasa.

\section{Metode}

\section{Sumber data}

Data yang digunakan dalam studi meta-analisis ini diperoleh dengan menggunakan database daring, yang ditelusuri dari www.lib.ugm.ac.id, dengan akses melalui ScienceDirect, SpringerLink, Pro-Quest, EBSCOhost, JSTOR dan Scopus. Kata kunci yang digunakan adalah executive function and school readiness, executive 
function and language dan executive function and vocabulary. Artikel-artikel yang diperoleh berdasarkan kata kunci tersebut diseleksi, dengan kriteria yang diambil sebagai sumber literatur adalah artikel jurnal yang mencantumkan dengan jelas nilai korelasi antara fungsi eksekutif dan bahasa. Rentang waktu yang diterapkan dalam penelitian ini berkisar antara tahun 2004 hingga 2017. Berdasarkan penelusuran awal, diperoleh 52 artikel dengan tujuh artikel yang mencantumkan lebih dari satu temuan korelasi antara fungsi eksekutif dengan bahasa. Setelah melalui tahap seleksi, secara keseluruhan digunakan 28 studi untuk dikaji menggunakan meta-analisis.

\section{Analisis data}

Analisis data dilakukan dengan menggunakan meta-analisis yaitu analisis data yang berasal dari studi primer. Hasil analisis dipakai sebagai dasar untuk menerima (mendukung) hipotesis atau menolak (menggugurkan) hipotesis serta memberikan petunjuk yang spesifik bagi penelitian selanjutnya (Sugiyanto, 2006). Meta-analisis dilakukan untuk melakukan sintesis beberapa penelitian yang diawali dengan melakukan koreksi terhadap artefak atau ketidaksempurnaan penelitian. Koreksi yang dilakukan dalam studi ini adalah bare bones meta-analysis atau koreksi terhadap kesalahan sampling, sementara koreksi terhadap kesalahan pengukuran tidak dilakukan karena sedikitnya studi yang mencantumkan reliabilitas alat ukur. Dari 17 artikel hanya ada 4 artikel yang mencantumkan reliabilitas alat ukur, sehingga jumlah tersebut dianggap kurang memadai untuk dilakukan koreksi kesalahan pengukuran. Bare bones meta-analysis untuk koreksi kesalahan sampel dilakukan dengan:

a. Menghitung rerata korelasi populasi

b. Menghitung varians $r_{x y}\left(\sigma^{2} r\right)$

c. Menghitung varians kesalahan pengambilan sampel $\left(\sigma^{2} \mathrm{e}\right)$

d. Dampak kesalahan pengambilan sampel

\section{Hasil}

\section{Karakteristik sampel penelitian}

Sampel penelitian yang dikaji dalam studi meta-analisis ini memiliki karakteristik seperti yang tercantum dalam Tabel 1. 
Tabel 1. Karakteristik Sampel Penelitian

\begin{tabular}{|c|c|c|c|c|c|}
\hline No & $\begin{array}{l}\text { Tahun } \\
\text { Studi }\end{array}$ & Peneliti & $\mathrm{N}$ & $\mathrm{r}$ & Karakteristik sampel \\
\hline 1 & 2005 & Roeber, C., M., \& Schneider, W. & 67 & 0,33 & Anak-anak \\
\hline 2 & 2008 & Figueras, B., Edwards, L., \& Langdon, D. & 41 & 0,59 & $\begin{array}{l}\text { Anak-anak usia 8-12 tahun, } \\
\text { tuli dengan Cochlear Implant } \\
\text { dan hearing aid }\end{array}$ \\
\hline 3 & 2008 & Figueras, B., Edwards, L., \& Langdon, D. & 19 & 0,52 & $\begin{array}{l}\text { Anak-anak usia 8-12 tahun, } \\
\text { pendengaran normal }\end{array}$ \\
\hline 4 & 2008 & Figueras, B., Edwards, L., \& Langdon, D. & 30 & 0,71 & $\begin{array}{l}\text { Anak-anak usia 8-12 tahun, } \\
\text { tuli dengan Cochlear Implant } \\
\text { dan hearing aid, dengan level } \\
\text { pendengaran }\end{array}$ \\
\hline 5 & 2012 & Dilworth-Bart, J.E. & 49 & 0,38 & Anak-anak usia 54-66 bulan \\
\hline 6 & 2013 & $\begin{array}{l}\text { Nesbitt, K. T., Baker-Ward Lynne, \& } \\
\text { Willoughby, M. T. }\end{array}$ & 206 & 0,75 & Anak-anak usia 6-36 bulan \\
\hline 7 & 2014 & Shaul, S., \& Schwartz, M. & 54 & 0,36 & Anak-anak usia 5-6 tahun \\
\hline 8 & 2014 & Shaul, S., \& Schwartz, M. & 31 & 0,23 & Anak-anak usia 5 tahun \\
\hline 9 & 2014 & Shaul, S., \& Schwartz, M. & 23 & 0,65 & Anak-anak usia 6 tahun \\
\hline 10 & 2014 & $\begin{array}{l}\text { Fitzpatrick, C., McKinnon, R. D., Blair, C. B., } \\
\text { \& Willoughby, M. T. }\end{array}$ & 226 & 0,48 & Anak-anak usia 36-66 bulan \\
\hline 11 & 2014 & Weiland, C., \& Yoshikawa, H. & 417 & 0,46 & Anak-anak \\
\hline 12 & 2014 & $\begin{array}{l}\text { Alarcon-Rubio, D., Sanchez-Medina, J.A., \& } \\
\text { Prieto-Garcia, J.R. }\end{array}$ & 81 & 0,35 & Anak-anak usia 4-7 tahun \\
\hline 13 & 2015 & Sasser, T. R., Bierman, K.L., \& Heinrich, B. & 164 & 0,28 & Anak-anak usia TK \\
\hline 14 & 2015 & Sasser, T. R., Bierman, K.L., \& Heinrich, B. & 164 & 0,32 & Anak-anak kelas 3 SD \\
\hline 15 & 2015 & $\begin{array}{l}\text { Moll, K., Snowling, M. J., Goble, S.M., \& } \\
\text { Hulme, C. }\end{array}$ & 76 & 0,33 & $\begin{array}{l}\text { Anak-anak usia 3-7 tahun } \\
\text { typically developing }\end{array}$ \\
\hline 16 & 2015 & $\begin{array}{l}\text { Moll, K., Snowling, M. J., Goble, S.M., \& } \\
\text { Hulme, C. }\end{array}$ & 93 & 0,41 & $\begin{array}{l}\text { Anak-anak usia 3-7 tahun } \\
\text { family risk dyslexia }\end{array}$ \\
\hline 17 & 2016 & $\begin{array}{l}\text { Kuhn, L. J., Willoughby, M. T., Vernon- } \\
\text { Feagans, L., Blair, C. B., \& The Family Life } \\
\text { Project Key Investigator }\end{array}$ & 1121 & 0,12 & Anak-anak usia 36 bulan \\
\hline 18 & 2016 & $\begin{array}{l}\text { Kuhn, L. J., Willoughby, M. T., Vernon- } \\
\text { Feagans, L., Blair, C. B., \& The Family Life } \\
\text { Project Key Investigator }\end{array}$ & 1121 & 0,22 & Anak-anak usia 48 bulan \\
\hline 19 & 2016 & $\begin{array}{l}\text { Kuhn, L. J., Willoughby, M. T., Vernon- } \\
\text { Feagans, L., Blair, C. B., \& The Family Life } \\
\text { Project Key Investigator }\end{array}$ & 1121 & 0,19 & Anak-anak usia 60 bulan \\
\hline 20 & 2016 & Zhang, X. & 109 & 0,22 & Anak-anak usia Pra-sekolah \\
\hline 21 & 2016 & $\begin{array}{l}\text { Baptista, J., Osorio, A., Martins, E.C., } \\
\text { Verissimo, M., \& Martins, C. }\end{array}$ & 69 & 0,57 & Anak-anak usia Pra-sekolah \\
\hline 22 & 2017 & $\begin{array}{l}\text { Willoughby, M.T., Magnus, B., Vernon- } \\
\text { Feagans, L., Blair, C. B., \& the Family Life } \\
\text { Project Investigator }\end{array}$ & 1292 & 0,23 & Anak-anak usia 3 tahun \\
\hline
\end{tabular}




\begin{tabular}{|c|c|c|c|c|c|}
\hline No & $\begin{array}{l}\text { Tahun } \\
\text { Studi }\end{array}$ & Peneliti & $\mathrm{N}$ & $\mathrm{r}$ & Karakteristik sampel \\
\hline 23 & 2017 & $\begin{array}{l}\text { Willoughby, M.T., Magnus, B., Vernon- } \\
\text { Feagans, L., Blair, C. B., \& the Family Life } \\
\text { Project Investigator }\end{array}$ & 1292 & 0,41 & Anak-anak usia 4 tahun \\
\hline 24 & 2017 & $\begin{array}{l}\text { Willoughby, M.T., Magnus, B., Vernon- } \\
\text { Feagans, L., Blair, C. B., \& the Family Life } \\
\text { Project Investigator }\end{array}$ & 1292 & 0,37 & Anak-anak usia 5 tahun \\
\hline 25 & 2017 & Vitiello, V. E., \& Greenfield, D. B. & 179 & 0,59 & $\begin{array}{l}\text { Anak-anak usia Pra-sekolah- } \\
\text { Spring }\end{array}$ \\
\hline 26 & 2017 & Vitiello, V. E., \& Greenfield, D. B. & 179 & 0,55 & $\begin{array}{l}\text { Anak-anak usia Pra-sekolah- } \\
\text { Fall }\end{array}$ \\
\hline 27 & 2017 & $\begin{array}{l}\text { White, L. J., Alexander, A., \& Greenfield, D. } \\
\text { B. }\end{array}$ & 182 & 0,42 & Anak-anak usia 3-5 tahun \\
\hline 28 & 2017 & $\begin{array}{l}\text { Teepe, C. R., Molenaar, I., Oostdam, R., } \\
\text { Fukkink, R., \& Verhoeven, L. }\end{array}$ & 223 & 0,56 & Anak-anak usia 2-4 tahun \\
\hline
\end{tabular}

Bare Bones Meta-analysis (Koreksi kesalahan pengambilan sampel)

Jika korelasi populasi diasumsikan konstan di antara beberapa studi, maka estimasi terbaik dari korelasi bukanlah rerata di antara studi-studi tersebut, melainkan rerata yang dibobot, yaitu setiap korelasi dibobot berdasar jumlah subjek dalam studi tersebut. a. Rerata korelasi populasi

Rerata korelasi populasi dihitung dengan menggunakan persamaan:

$$
\check{\mathbf{r}}=\frac{\Sigma\left(N_{i} r_{i}\right)}{\Sigma N_{i}}
$$

Berdasarkan formula tersebut maka dilakukan perhitungan untuk mendapatkan rerata korelasi populasi berdasarkan nilai ri atau rxy dan jumlah sampel (N) pada masing-masing studi. Hasil perhitungan ditunjukkan pada tabel 2 . 
Tabel 2. Koreksi kesalahan sampel

\begin{tabular}{|c|c|c|c|}
\hline No Studi & $\mathrm{N}$ & $r_{i}$ & $\mathrm{Nxr}_{\mathrm{i}}$ \\
\hline 1 & 67 & 0,33 & 22,11 \\
\hline 2 & 41 & 0,59 & 24,19 \\
\hline 3 & 19 & 0,52 & 9,88 \\
\hline 4 & 30 & 0,71 & 21,3 \\
\hline 5 & 49 & 0,38 & 18,62 \\
\hline 6 & 226 & 0,48 & 108,48 \\
\hline 7 & 54 & 0,36 & 19,44 \\
\hline 8 & 31 & 0,23 & 7,13 \\
\hline 9 & 23 & 0,65 & 14,95 \\
\hline 10 & 206 & 0,75 & 154,5 \\
\hline 11 & 417 & 0,46 & 191,82 \\
\hline 12 & 81 & 0,35 & 28,35 \\
\hline 13 & 164 & 0,28 & 45,92 \\
\hline 14 & 164 & 0,32 & 52,48 \\
\hline 15 & 76 & 0,33 & 25,08 \\
\hline 16 & 93 & 0,41 & 38,13 \\
\hline 17 & 1121 & 0,12 & 134,52 \\
\hline 18 & 1121 & 0,22 & 246,62 \\
\hline 19 & 1121 & 0,19 & 212,99 \\
\hline 20 & 109 & 0,22 & 23,98 \\
\hline 21 & 69 & 0,57 & 39,33 \\
\hline 22 & 1292 & 0,23 & 297,16 \\
\hline 23 & 1292 & 0,41 & 529,72 \\
\hline 24 & 1292 & 0,37 & 478,04 \\
\hline 25 & 179 & 0,59 & 105,61 \\
\hline 26 & 179 & 0,55 & 98,45 \\
\hline 27 & 182 & 0,42 & 76,44 \\
\hline 28 & 223 & 0,56 & 124,88 \\
\hline \multirow[t]{2}{*}{ Jumlah } & 9921 & 11,6 & 3150,12 \\
\hline & & $\check{r}$ & 0,318 \\
\hline
\end{tabular}

Dengan jumlah sampel 9921, rerata korelasi populasi setelah dikoreksi (ř) adalah 0,318.

b. Varians $r_{x y}\left(\sigma^{2} r\right)$

Varians $r_{x y}\left(\sigma^{2} r\right)$ dihitung dengan

menggunakan persamaan:

$\sigma^{2} \mathbf{r}=\Sigma\left[\mathbf{N}_{\mathrm{i}}\left(\mathbf{r}_{\mathrm{i}}-\check{\mathbf{r}}\right)^{2}\right]$
Hasil perhitungan varians $r_{x y}\left(\sigma^{2} r\right)$ disajikan dalam tabel 3. 
Tabel 3. Varians $\mathrm{r}_{\mathrm{xy}}$

\begin{tabular}{|c|c|c|c|c|c|}
\hline No Studi & $\mathrm{N}$ & $\mathrm{r}_{\mathrm{i}}$ & $\left(\mathrm{r}_{\mathrm{i}}-\mathrm{r}\right)$ & $\left(r_{i}-r\right)^{2}$ & $N\left(r_{i}-r\right){ }^{2}$ \\
\hline 1 & 67 & 0,33 & 0,01 & 0,00 & 0,01 \\
\hline 2 & 41 & 0,59 & 0,27 & 0,07 & 3,04 \\
\hline 3 & 19 & 0,52 & 0,20 & 0,04 & 0,78 \\
\hline 4 & 30 & 0,71 & 0,39 & 0,15 & 4,62 \\
\hline 5 & 49 & 0,38 & 0,06 & 0,00 & 0,19 \\
\hline 6 & 226 & 0,48 & 0,16 & 0,03 & 5,97 \\
\hline 7 & 54 & 0,36 & 0,04 & 0,00 & 0,10 \\
\hline 8 & 31 & 0,23 & $-0,09$ & 0,01 & 0,24 \\
\hline 9 & 23 & 0,65 & 0,33 & 0,11 & 2,54 \\
\hline 10 & 206 & 0,75 & 0,43 & 0,19 & 38,53 \\
\hline 11 & 417 & 0,46 & 0,14 & 0,02 & 8,47 \\
\hline 12 & 81 & 0,35 & 0,03 & 0,00 & 0,09 \\
\hline 13 & 164 & 0,28 & $-0,04$ & 0,00 & 0,23 \\
\hline 14 & 164 & 0,32 & 0,00 & 0,00 & 0,00 \\
\hline 15 & 76 & 0,33 & 0,01 & 0,00 & 0,01 \\
\hline 16 & 93 & 0,41 & 0,09 & 0,01 & 0,80 \\
\hline 17 & 1121 & 0,12 & $-0,20$ & 0,04 & 43,73 \\
\hline 18 & 1121 & 0,22 & $-0,10$ & 0,01 & 10,66 \\
\hline 19 & 1121 & 0,19 & $-0,13$ & 0,02 & 18,22 \\
\hline 20 & 109 & 0,22 & $-0,10$ & 0,01 & 1,04 \\
\hline 21 & 69 & 0,57 & 0,25 & 0,06 & 4,40 \\
\hline 22 & 1292 & 0,23 & $-0,09$ & 0,01 & 9,89 \\
\hline 23 & 1292 & 0,41 & 0,09 & 0,01 & 11,05 \\
\hline 24 & 1292 & 0,37 & 0,05 & 0,00 & 3,56 \\
\hline 25 & 179 & 0,59 & 0,27 & 0,07 & 13,29 \\
\hline 26 & 179 & 0,55 & 0,23 & 0,05 & 9,68 \\
\hline 27 & 182 & 0,42 & 0,10 & 0,01 & 1,91 \\
\hline 28 & 223 & 0,56 & 0,24 & 0,06 & 13,11 \\
\hline Jumlah & 9921 & 11,6 & 2,71 & 0,99 & 206,16 \\
\hline Rerata & 354 & & & Varians $r_{x y}$ & 0,021 \\
\hline
\end{tabular}

Berdasarkan tabel 3 tersebut diketahui bahwa Varians $r_{x y}\left(\sigma^{2} r\right)$ adalah 0,021. 
c. Varians kesalahan pengambilan sampel $\left(\sigma^{2} e\right)$

Varians kesalahan pengambilan sampel $\left(\sigma^{2} e\right)$ dapat dihitung dengan menggunakan persamaan:

$\sigma^{2} \mathbf{e}=\left(1-\check{\mathbf{r}}^{2}\right)^{2}$

$$
\text { ( }
$$

Berdasarkan nilai ř yang diperoleh dan rerata jumlah sampel ( $\mathrm{N})$ yang ada, maka varians kesalahan pengambilan sampel $\left(\sigma^{2} e\right)$ pada studi meta-analisis ini adalah:

$\sigma^{2} e={\underline{\left(1-0,318^{2}\right)^{2}}}^{(354-1)}$

(354 - 1)

$\sigma^{2} e=(0,899)^{2}$

353

$\sigma^{2} e=0,002$

Berdasarkan perhitungan tersebut diketahui bahwa varians kesalahan pengambilan sampel $\left(\sigma^{2} e\right)$ adalah sebesar 0,002 .

d. Estimasi varians korelasi populasi Varians korelasi populasi merupakan varians yang dikoreksi, yang diperoleh dengan menghitung varians korelasi dikurangi varians kesalahan pengambilan sampel. Varians korelasi populasi dapat dihitung dengan menggunakan persamaan:

$\sigma^{2} \rho=\sigma^{2} \mathbf{r}-\sigma^{2} e$

$\sigma^{2} \rho=0,021-0,002$

$\sigma^{2} \rho=0,019$ e. Interval kepercayaan

Interval kepercayaan dapat dihitung dengan persamaan:

$\check{\mathbf{r}} \pm 1,96 \mathrm{SD}$

$\check{\mathbf{r}} \pm 1,96 \times 0,144$

$\check{\mathbf{r}} \pm \mathbf{0 , 2 8 2}$

$0,318 \pm 0,282$

$0,036<\check{\mathbf{r}}<0,600$

f. Dampak kesalahan pengambilan sampel

Dampak kesalahan pengambilan sampel dapat dilihat berdasarkan persamaan:

Dampak $=\sigma 2 e \times 100 \%$

$$
\overline{\sigma 2 \rho}
$$

$=0,002 \times 100 \%=$ $\overline{\mathbf{0 , 0 1 9}}$ $=10,52 \%$

Berdasarkan perhitungan tersebut dapat diketahui bahwa dampak kesalahan pengambilan sampel adalah sebesar 10,52 \%.

\section{Pembahasan}

Dari hasil analisis data pada studi meta-analisis berdasarkan bare bones meta analysis mengenai fungsi eksekutif dengan bahasa diperoleh korelasi populasi (ř) setelah dikoreksi oleh kesalahan sampel sebesar 0,318, variasi kesalahan pengambilan sampel sebesar 0,002 , dengan SD sebesar 0,144, dan masuk dalam rentang kepercayaan 95\%, dalam batas penerimaan $0,036<\breve{\mathrm{r}}<0,600$. Hasil korelasi antara fungsi eksekutif dengan bahasa sebesar 
0,318 menunjukkan bahwa hubungan tersebut tergolong sedang, sehingga hipotesis yang menyatakan ada hubungan antara fungsi eksekutif dan bahasa dapat diterima.

Temuan dari studi meta-analisis ini memperkuat temuan-temuan dari penelitian-penelitian terdahulu mengenai adanya hubungan antara fungsi eksekutif dan bahasa. Trainor (2010) melakukan penelitian mengenai hubungan antara fungsi eksekutif dan kemampuan bahasa naratif pada anak prasekolah dan menemukan hubungan yang kuat antara naratif oral dengan fungsi eksekutif, khususnya metakognisi yang melibatkan working memory dan perencanaan, serta menunjukkan hubungan antara fungsi eksekutif dan bahasa ekspresif. Tidak jauh berbeda dengan temuan Lambeth dan Liesen (2011) juga menemukan adanya hubungan yang kuat antara fungsi eksekutif dan kemampuan bahasa naratif pada anak usia sekolah, sementara Simlesa, Cepanec, dan Ljubesic (2017) menekankan pentingnya peran fungsi eksekutif, terutama working memory, dalam pemahaman bahasa dan pembelajaran bahasa di masa prasekolah. Sejumlah penelitian yang sudah dilakukan tersebut menegaskan bahwa hubungan antara fungsi eksekutif dan bahasa tidak dapat disangkal lagi (Morgan, 2015).

Di tahun-tahun awal perkembangan bahasa, fungsi eksekutif membantu anak fokus pada beragam arus informasi yang hadir pada saat bersamaan, memonitor kesalahan, dan membuat keputusan berdasarkan informasi yang tersedia, yang kesemuanya itu penting bagi pemerolehan dan perkembangan keterampilan bahasa (Diamond, 2013). Baddeley dan Hitch (1974) memaparkan model mengenai keterhubungan antara fungsi eksekutif dan bahasa melalui penjelasan mengenai working memory sebagai salah satu komponen fungsi eksekutif dengan pemahaman bahasa. Dalam model working memory ini penting diketahui adanya phonological loop yang menyimpan informasi verbal yang diterima. Pemahaman mengenai keterhubungan antara fungsi eksekutif dan bahasa ini penting untuk memberikan perlakuan yang sesuai bagi anak sehingga dapat mendukung proses kesiapan sekolah.

Beberapa studi yang digunakan dalam studi meta-analisis ini melibatkan subjek dengan gangguan pendengaran, sehingga temuan ini juga membantu memberikan informasi yang dapat digunakan untuk mengupayakan intervensi yang tepat bagi anak dengan keterbatasan dalam penggunaan bahasa (Simlesa, Cepanec, \& Ljubesic, 2017). Cleary, Pisoni dan Geers (2001) memaparkan bahwa anak dengan gangguan pendengaran memiliki performa fungsi eksekutif di bawah anakanak yang memiliki pendengaran normal. Dengan diketahui adanya hubungan antara 
fungsi eksekutif dan bahasa, maka perencanaan perlakuan yang melibatkan intervensi dalam fungsi eksekutif untuk meningkatkan kemampuan dan keterampilan bahasa dapat dilakukan secara lebih cermat.

\section{Simpulan}

Studi meta-analisis yang dilakukan ini menguatkan penelitian-penelitian terdahulu mengenai adanya hubungan antara fungsi eksekutif dan bahasa dengan kategori nilai korelasi yang tergolong sedang. Meski demikian, studi ini terbatas hanya pada sampel anak-anak tanpa ada sampel remaja maupun dewasa. Karenanya disarankan untuk dapat memperluas cakupan sampel sehingga informasi mengenai hubungan antara fungsi eksekutif dan bahasa tidak terbatas hanya pada sampel anak-anak saja. Selain itu, studi ini juga melibatkan sampel anak dengan gangguan pendengaran namun hanya terbatas pada beberapa studi saja, sehingga disarankan untuk memperbanyak studi dengan sampel anak dengan gangguan pendengaran dan membuat pengelompokan sesuai dengan karakteristik tersebut. Dengan adanya pengelompokan antara anak tanpa gangguan pendengaran dengan yang memiliki gangguan pendengaran diharapkan akan semakin memperjelas pemaknaan dalam memahami hubungan antara fungsi eksekutif dan bahasa. Studi meta-analisis ini hanya menggunakan bare bones meta analysis karena terbatasnya jumlah studi yang menyertakan reliabilitas alat ukur dalam pelaporannya. Penambahan jumlah studi yang menyertakan informasi mengenai reliabilitas alat ukur sangat disarankan agar koreksi kesalahan pengukuran dapat dilakukan.

\section{Daftar Pustaka}

Baddeley, A. D., \& Hitch, G. J. (1974). Working memory. psychology of learning and motivation. New York: Academic Press.

Bishop, D.V.M., Nation, K., \& Patterson, K. (2014). When words fail us: Insights into language processing from developmental and acquired disorders. Philosophical transactions of the Royal Society of London. Series B, Biological Sciences, 369(1634), 111.

Blair, C. (2002). School readiness: Integrating cognition and emotion in a neurobiological conceptualization of child functioning at school entry. American Psychologist, 57, 111-127.

Blair, C., \& Razza, R. P. (2007). Relating effortful control, executive function, and false belief understanding to emerging math and literacy ability in kindergarten. Child Development, 78, 647-663.

Cleary, M., Pisoni, D., \& Geers, A. (2001). Some measures of verbal and spatial working memory in eight- and nineyear-old hearing-impaired children with cochlear implants. Ear and Hearing, 22, 395-411.

Diamond, A. (2013). Executive functions. Annual Review of Psychology, 64, 135168. 
Engle, R. W. (2010). Role of working memory capacity in cognitive control. Current Anthropology, 51, 517-526.

Fitzpatrick, C. (2012). Ready or not: Kindergarten classroom engagement as an indicator of child school readiness. South African Journal of Childhood Education, 2(1), 1-32.

Grove, M. C., Hauptfleisch, H.M.A.M. (2005). Getting ready: National school readiness indicators report. Rhodes Island: Rhodes Island Kids Count.

Guralnick, M. J. (2011) Why Early Intervention Works: A Systems Perspective. Infants and Young Children, 24, 6-28.

Henry, L.A., Messer, D.J., \& Nash, G. (2012). Executive functioning in children with specific language impairment. Journal of Child Psychology and Psychiatry, 53, 37-45.

Hughes, C., \& Graham, A. (2002). Measuring executive functions in childhood: Problems and solutions? Child and Adolescent Mental Health, 7, 131-142.

Hunter, J. E., \& Schmidt, F. L. (2014). Methods of meta-analysis: Correcting Error and Bias in Research Findings (3nd ed.). Newbury Park, CA: Sage Publications.

Kendall-Taylor, N., Erard, M., Davey, L., \& Simon, A. (2010). Air traffic control for your brain: Translating the science of executive function using a simplifying model. Washington, DC: FrameWorks Institute.
Lambeth, S., \& Liesen, J. (2011). Relationship between School-Age Executive Function and Language Skills. American Speech Language Hearing Association. Diunduh dari https://www.asha.org/Events/conve ntion/2011/Lambeth-Liesen.

Morgan, G. (2015). Language cognition dependencies. Language Learning and Development, 4(3), 1-9.

Morra, S., \& Camba, R. (2009). Vocabulary learning in primary school children: Working memory and long-term memory components. Journal of Experimental Child Psychology, 104, 156-178.

Muter, V., Hulme, C., Snowling, M. J., \& Stevenson, J. (2004). Phonemes, rimes, vocabulary, and grammatical skills as foundations of early reading development: Evidence from a longitudinal study. Developmental Psychology, 40(5), 665-681.

Rojas-Barahona, C. A., Förster, C. E., Moreno-Ríos, S., \& McClelland, M. M. (2015). Improvement of working memory in preschoolers and its impact on early literacy skills: A study in deprived communities of rural and urban areas. Early Education and Development, 26, 871-892.

Simlesa, S., Cepanec, M., \& Ljubesic, M. (2017). The role of executive functions in language comprehension in preschool children. Psychology, 8, 227-245.

Stackhouse, J., (1997). Children's speech and literacy difficulties: A Psycholinguistic Framework. UK: Wiley Publisher. 
Sugiyanto. (2006). Meta-analisis: Bahan perkuliahan metode kuantitatif. (Tidak dipublikasikan). Yogyakarta: Fakultas Psikologi UGM

Tannock, R. and Schachar, R. (1996). Executive dysfunction as an underlying mechanism of behavior and language problems in attentiondeficit/hyperactivity disorder. In: J.H. Beitchman, N.J. Cohen, M.M. Konstantareas and R. Tannock (eds.). Language, learning and behavioral disorder: Developmental, biological and clinical perspectives. Cambridge: Cambridge University Press.

Trainor, K. (2010). The relationship between preschool executive function skills and oral narrative skills (Unpublished manuscript), Department of Communication Disorders and Sciences, Eastern Illinois University, Charleston, Illinois.

Ursache, A., Blair, C.B., Raver, C.C. (2012). The promotion of self-regulation as a means of enhancing school readiness and early achievement in children at risk for school failure. Child Development Perspectives, 6(2), 122128.

Verhagen, J., \& Leseman, P. (2016). How do verbal short-term memory and working memory relate to the acquisition of vocabulary andgrammar? Acomparison between first and second language learners. Journal of Experimental Child Psychology, 141, 65-82.

Ye, Z., \& Zhou, X. (2008). Involvement of cognitive control insentence comprehension: Evidence from ERPs. Brain Research, 1203, 103115. 